\title{
The Fracture of Glass-Fibre Reinforced Epoxy Composites using Nanoparticle-Modified Matrices
}

\author{
A.J. Kinloch, K. Masania and A.C. Taylor \\ Department of Mechanical Engineering, South Kensington Campus, Imperial College \\ London, London SW7 2AZ, UK. \\ S.Sprenger \\ Nanoresins AG, Charlottenburger Str. 9, 21502 Geesthacht, Germany \\ D.Egan \\ Emerald Performance Materials Inc., 9911 Brecksville Rd., Cleveland, OH 44141, USA \\ (a.c.taylor@imperial.ac.uk)
}

Keywords: composites, epoxy polymers, interlaminar toughness, nano-materials, rubbertoughened, mode I, mode II, fracture.

\section{Introduction}

The epoxy polymers used as adhesives and as the matrices of composite materials are amorphous and highly-crosslinked (thermosetting) materials. This microstructure results in many useful properties, such as a high modulus and failure strength, low creep, and good performance at elevated temperatures. However, this microstructure also leads to one highly undesirable property in that they are relatively brittle materials, with a poor resistance to crack initiation and growth.

These materials can be toughened by the incorporation of a micro-phase of a dispersed rubbery, e.g. [1-3] or thermoplastic polymer, e.g. [4-6], without significantly impairing the other desirable properties of the epoxy polymer. These modifiers are soluble in the epoxy prior to crosslinking. Hence, as long as the modifiers do not increase the viscosity of the resin significantly, this method of toughening may be used with resin-infusion processes for the production of fibre composite materials. These processes are attractive for the production of the next generation of composite materials due to their relatively low tooling 
costs. However, the addition of these rubbery and thermoplastic modifiers, at the concentrations required to achieve significant toughness increases, typically does lead to an increase in the viscosity of the epoxy which may be unacceptable for resin-infusion processes.

The addition of rigid particles has also been shown to increase the toughness of thermosetting polymers [7-9]. However, these particles have conventionally been tens of microns in diameter, and hence are not suitable for use with resin-infusion processes, as they are larger than the inter-fibre spacing. Indeed, they are strained out of the resin by the fibres during infusion. More recently, the availability of nanometre-sized particles has allowed rigid particles to be used in the formulation of resins for use with infusion processes, e.g. [10]. The authors have previously shown that fibre composites may be successfully manufactured using $20 \mathrm{~nm}$ diameter silica nanoparticles, and that these particles increase the toughness of the material [11].

The formation of 'hybrid-toughened' epoxy polymers, by combining both rubber toughening and silica nanoparticles has been shown to give a synergistic toughening effect $[12,13]$. The results of mode I and mode II fracture tests on a glass-fibre reinforced polymer (GFRP) composite produced by a resin infusion under flexible tooling (RIFT) process are reported in the present paper.

\section{Experimental}

\subsection{Materials}

The materials were based upon a single-component hot-cured epoxy formulation. The epoxy resin was a standard diglycidyl ether of bis-phenol A (DGEBA) with an epoxy equivalent weight (EEW) of 175 g/mol, 'DER332' (Dow Chemical Company, Midland, USA). The silica nanoparticles were obtained at a concentration of $40 \mathrm{wt} \%$ in this DGEBA epoxy resin: 'Nanopox F400' (Nanoresins, Geesthacht, Germany). These organosilane-modified $\mathrm{SiO}_{2}$ nanoparticles had an average particle size of about $20 \mathrm{~nm}$, with a narrow range of particle-size distribution [10]. Further, despite the relatively high silica content of $40 \mathrm{wt} . \%$, the nano-filled epoxy resin still has a comparatively low viscosity due to the agglomerate-free colloidal dispersion of the nanosilica in the epoxy resin. 
The reactive liquid rubber was a carboxyl-terminated butadiene-acrylonitrile (CTBN) rubber: 'Hycar CTBN 1300x8' (Emerald Performance Materials, Cleveland, USA). This has a number-average molecular weight of $3,550 \mathrm{~g} / \mathrm{mol}$ and an acrylonitrile content of 18 wt.\%. This was pre-reacted with the DEGBA resin to give a 40 wt.\% CTBN-epoxy adduct: 'Albipox 1000' (Nanoresins, Geesthacht, Germany). The curing agent was an accelerated methylhexahydrophthalic acid anhydride: 'Albidur HE 600' (Nanoresins, Geesthacht, Germany).

The formulations were prepared by mixing together the DGEBA epoxy with given amounts of the nanosilica-epoxy and CTBN-epoxy adduct, to give the required levels of nanoparticles and rubber. The value of the EEW of the blend was calculated, and a stoichiometric amount of the curing agent was added to the mixture. The formulations used are shown in Table 1.

The GFRP composite panels were manufactured by resin infusion under flexible tooling (RIFT). The glass fibre was a non-crimp unidirectional glass fabric with polyester weft stitching: 'UT-E500' (SP Systems, Eastleigh, UK). Composite plates approximately $7 \mathrm{~mm}$ thick were prepared using 16 plies of the fabric, laid up in a unidirectional orientation on an aluminium baseplate. The infusion stack comprised a base sheet of poly(ethylene terephthalate) followed by flow media, peel ply, dry fibres, peel ply, flow media and a final sheet of peel ply [14]. A thin film of poly(tetrafluoroethylene) (PTFE) was inserted into the fabric prior to resin infusion, along one side of the GFRP plate to a length of $35 \mathrm{~mm}$, to act as a starter crack for the fracture specimens. The infusion stack was encased in a vacuum bag, using a pressure-sensitive adhesive tape to seal the mould. The resin was degassed, and then drawn through the fibres at $50^{\circ} \mathrm{C}$, using the vacuum to achieve a composite that is free of voids [15]. Once infusion was complete, the plates were cured for 2 hours at $100^{\circ} \mathrm{C}$, followed by a post-cure of 10 hours at $150^{\circ} \mathrm{C}$ and subsequent cooling to room temperature.

It again should be emphasised that the lack of a significant increase in the viscosity of the epoxy resin, containing even $10 \mathrm{wt} . \%$ of silica nanoparticles, enabled this range of resins to be readily used in a RIFT manufacturing process. 
After curing the composite panels were sectioned and observed using reflection optical microscopy. The panels were void-free, and mean volume fraction of the fibres was calculated to be approximately $57 \%$ for all of the composites.

\subsection{Thermal and Mechanical Properties of the Composites}

The glass transition temperature, $T_{g}$, of the composites was measured using differential scanning calorimetry at a rate of $10^{\circ} \mathrm{C} /$ minute. Flexural modulus tests were conducted in three point bending, in accordance with ASTM D790M [16], using 6mm diameter supports at a span of $120 \mathrm{~mm}$, and at a constant strain rate of $0.01 \mathrm{~min}^{-1}$.

\subsection{Fracture Performance of the Composites}

Double cantilever beam (DCB) specimens were used to measure the interlaminar fracture energy, $G_{I C}$, under mode I loading conditions according to the ASTM test method [17]. The specimens were machined to be $230 \mathrm{~mm}$ long by $20 \mathrm{~mm}$ wide, and approximately $7 \mathrm{~mm}$ thick. Tests were performed using a servo-electric universal testing machine at a test rate of $1 \mathrm{~mm} / \mathrm{min}$. The results were analysed using the corrected beam theory (CBT) method [18].

End-loaded split (ELS) tests were used to measure the mode II interlaminar fracture energy, $G_{\| c}$. This method is preferred to the end-notched flexure (ENF) method as it produces more stable crack propagation [19]. These mode II tests were conducted using a servo-electric universal testing machine at a test rate of $1 \mathrm{~mm} / \mathrm{min}$. Tests have been conducted in accordance with Wang \& Vu-Khanh [20] and Blackman et al [21]. The results were analysed using the 'corrected-beam theory with calculated modulus (CBTE)' method, see [21].

\section{Results}

\subsection{Thermal and Mechanical Properties of the Composites}

The glass transition temperature, $T_{g}$, of the control composite was $135^{\circ} \mathrm{C}$, as shown in Table 1. The results show that $T_{g}$ is very similar for each formulation, at $133 \pm 4^{\circ} \mathrm{C}$, and 
that the addition of rubber or nanosilica has little effect on the glass transition temperature of the epoxy.

The flexural modulus tests showed that there is little difference between the modulus of the composites, as the modulus is dominated by the presence of the fibres, as shown in Table 1. This effect has also been observed for similar carbon-fibre reinforced epoxies [11]. A mean value of approximately $40 \mathrm{GPa}$ was measured. These tests also showed that the flexural modulus is consistent across a plate, indicating that the plates are homogeneous.

\subsection{Mode I Fracture Performance of the Composites}

Table 1 shows the measured mode I initiation fracture energy values for the various formulations of GFRP. Extensive fibre-bridging was observed, and resistance curves (Rcurves) were observed for all samples. As the measured fracture energies increase significantly with crack length, the initiation values are quoted. A fracture energy of 330 $\mathrm{J} / \mathrm{m}^{2}$ was measured for the control composite.

The addition of 9 wt.\% of CTBN increases the fracture energy of the epoxy significantly, a mean value of $885 \mathrm{~J} / \mathrm{m}^{2}$ being recorded. The CTBN undergoes reaction-induced phaseseparation upon curing of the epoxy to produce rubbery particles of about $0.5 \mu \mathrm{m}$ in diameter (as is well documented for such materials [2, 3]). The addition of silica nanoparticles to the rubber-toughened epoxy, to give a hybrid-toughened epoxy matrix, gives a similar toughness. A fracture energy of $860 \mathrm{~J} / \mathrm{m}^{2}$ was measured.

The addition of $10 \mathrm{wt} \%$ of silica nanoparticles to the unmodified epoxy also gives a significant toughening effect. A mode I fracture energy of $1015 \mathrm{~J} / \mathrm{m}^{2}$ was measured. This is an increase of over $200 \%$ compared to the control composite.

\subsection{Mode I Fracture Performance: Interlaminar versus Bulk}

The mode I interlaminar fracture energy values for the various formulations of GFRP are plotted against the corresponding values for the bulk material, as reported by Kinloch et al [13], in Figure 1. These data show that the fracture energy of the composites prepared 
with the control, and the CTBN- or nanosilica-modified formulations is greater than the bulk value of $G_{I C}$. The hybrid formulation shows a considerable synergistic toughening effect for the bulk polymer. However, the measured $G_{I C}$ for the hybrid composite is lower than that of the bulk. A similar effect has been reported by Hunston et al [22], who observed that thermoset polymers which have a high bulk toughness do not necessarily give high composite fracture energies. They reported that, at low fracture energies, the bulk polymer toughness is transferred fully to the composite. However, above a threshold value of $G_{I C}$ of approximately $750 \mathrm{~J} / \mathrm{m}^{2}$, although the bulk toughness increases, this increase is not fully transferred to the composite. The results in the present work agree well with this proposition. Hunston et al suggested that for the high-toughness composites, the fibres restrict the size of the crack-tip deformation zones, and hence limit the interlaminar fracture energy.

\subsection{Mode II Fracture Performance of the Composites}

The results of the mode II fracture tests are summarised in Table 1. The control composite gave an interlaminar fracture energy, $G_{I I C}$, of $1160 \mathrm{~J} / \mathrm{m}^{2}$. The addition of CTBN increased the mean value of $G_{I I C}$, although the overlap of the standard deviations means that this is not a significant increase.

The addition of silica nanoparticles to the unmodified epoxy gave a significant toughening effect, and a mode II fracture energy of $1770 \mathrm{~J} / \mathrm{m}^{2}$ was measured.

The hybrid-toughened epoxy matrix exhibits the highest toughness in mode II, a fracture energy of $1895 \mathrm{~J} / \mathrm{m}^{2}$ being measured. This is an increase of over $60 \%$ compared to the control composite.

The relationship between the interlaminar values of $G_{I C}$ and $G_{I I C}$ of the GFRP composites is shown in Figure 2. The results given in this figure clearly reveal the significant toughening of the composite by the rubbery CTBN phase present in the epoxy polymer; and the further enhanced values of $G_{C}$ when the 'hybrid-toughened' epoxy polymer is employed. Thus, the synergistic effect of having a multiphase structure based upon both silica nanoparticles and micron-sized rubbery domains is again demonstrated $[12,13]$. 


\section{Conclusions}

The use of silica nanoparticles and micron-sized rubbery particles to form hybridtoughened epoxy polymers has been shown to give a range of novel matrices, which can be used to manufacture composite laminates by a resin infusion under flexible tooling (RIFT) process. The presence of the rubber and nanoparticles does not significantly decrease the flexural modulus or the glass transition temperature of the composite. However, these formulations show a significant increase in the interlaminar fracture energy in both mode I and mode II fracture of glass-fibre reinforced composites.

\section{Acknowledgments}

The authors wish to thank the EPSRC for a doctoral training award for Mr. K. Masania, and to acknowledge the general support from the US Army European Research Office.

\section{References}

1. R.S. Drake and A.R. Siebert, SAMPE Quarterly 6 (1975) 11.

2. A.J. Kinloch, S.J. Shaw, D.A. Tod and D.L. Hunston, Polymer 24 (1983) 1341.

3. A.F. Yee and R.A. Pearson, J. Mater. Sci. 21 (1986) 2462.

4. C.B. Bucknall and A.H. Gilbert, Polymer 30 (1989) 213.

5. A.J. Kinloch, M.L. Yuen and S.D. Jenkins, J. Mater. Sci. 29 (1994) 3781.

6. B.B. Johnsen, A.J. Kinloch and A.C. Taylor, Polymer 46 (2005) 7352.

7. L.J. Broutman and S. Sahu, Mater. Sci. Eng. 8 (1971) 98.

8. J. Spanoudakis and R.J. Young, J. Mater. Sci. 19 (1984) 473.

9. A.J. Kinloch and A.C. Taylor, J. Mater. Sci. 37 (2002) 433.

10. B.B. Johnsen, A.J. Kinloch, R.D. Mohammed, A.C. Taylor and S. Sprenger, Polymer 48 (2007) 530.

11. A.J. Kinloch, R.D. Mohammed, A.C. Taylor, S. Sprenger and D. Egan, J. Mater. Sci. 41 (2006) 5043.

12. A.J. Kinloch, J.H. Lee, A.C. Taylor, S. Sprenger, C. Eger and D. Egan, J. Adhesion 79 (2003) 867.

13. A.J. Kinloch, R.D. Mohammed, A.C. Taylor, C. Eger, S. Sprenger and D. Egan, J. Mater. Sci. 40 (2005) 5083.

14. M.V. Donadon, B.G. Falzon, L. Iannucci and J.M. Hodgkinson, Composites Part A: Applied Science and Manufacturing 38 (2007) 1597. 
15. C. Williams, J. Summerscales and S. Grove, Composites Part A: Applied Science and Manufacturing 27 (1996) 517.

16. ASTM-D790 "Standard Test Methods for Flexural Properties of Unreinforced and Reinforced Plastics and Electrical Insulating Materials", West Conshohocken, 2003).

17. ASTM-D5528 "Standard Test Method for Mode I Interlaminar Fracture Toughness of Unidirectional Fiber-Reinforced Polymer Matrix Composites" (ASTM, West Conshohocken, 2001).

18. ISO-15024 "Determination of the Mode I Delamination Resistance of Unidirectional FiberReinforced Polymer Laminates Using the Double Cantilever Beam (DCB)" (ISO, Geneva, 1999).

19. P. Davies, B.R.K. Blackman and A.J. Brunner, Appl. Composite Mater. 5 (1998) 345.

20. H. Wang and T. Vukhanh, Composite Structures 36 (1996) 71.

21. B.R.K. Blackman, A.J. Brunner and J.G. Williams, Eng. Fract. Mech. 73 (2006) 2443.

22. D.L. Hunston, R.J. Moulton, N.J. Johnston and W.D. Bascom, in "Toughened Composites" edited by N. J. Johnston (ASTM, Philadelphia, 1985) p. 74. 
Table 1. The formulations employed for the GFRP composites, their glass transition temperatures, flexural modulus values, and mode I \& mode II initiation values of interlaminar fracture energy, $G_{c}$. Mean and standard deviation are shown.

\begin{tabular}{|c|c|c|c|c|c|c|c|c|c|}
\hline \multicolumn{3}{|c|}{ Formulation } & $T_{g}$ & \multicolumn{2}{c|}{$\mathrm{E}_{\mathrm{f}}, \mathrm{GPa}$} & \multicolumn{2}{|c|}{$\mathrm{G}_{\mathrm{IC} \text { INT, }} \mathrm{J} / \mathrm{m}^{2}$} & \multicolumn{2}{|c|}{$\mathrm{G}_{\text {IIC INT, }} \mathrm{J} / \mathrm{m}^{2}$} \\
\hline Name & $\begin{array}{c}\text { wt.\% } \\
\text { nanosilica }\end{array}$ & $\begin{array}{c}\text { wt.\% } \\
\text { CTBN }\end{array}$ & ${ }^{\circ} \mathrm{C}$ & Mean & $\sigma$ & Mean & $\sigma$ & Mean & $\sigma$ \\
\hline Control & 0 & 0 & 135 & 39.7 & 2.8 & 330 & 150 & 1160 & 315 \\
\hline CTBN & 0 & 9 & 137 & 39.1 & 1.9 & 885 & 60 & 1460 & 100 \\
\hline Nanosilica & 10 & 0 & 133 & 38.5 & 3.3 & 1015 & 195 & 1770 & 50 \\
\hline Hybrid & 10 & 9 & 130 & 40.6 & 1.8 & 860 & 90 & 1895 & 320 \\
\hline
\end{tabular}




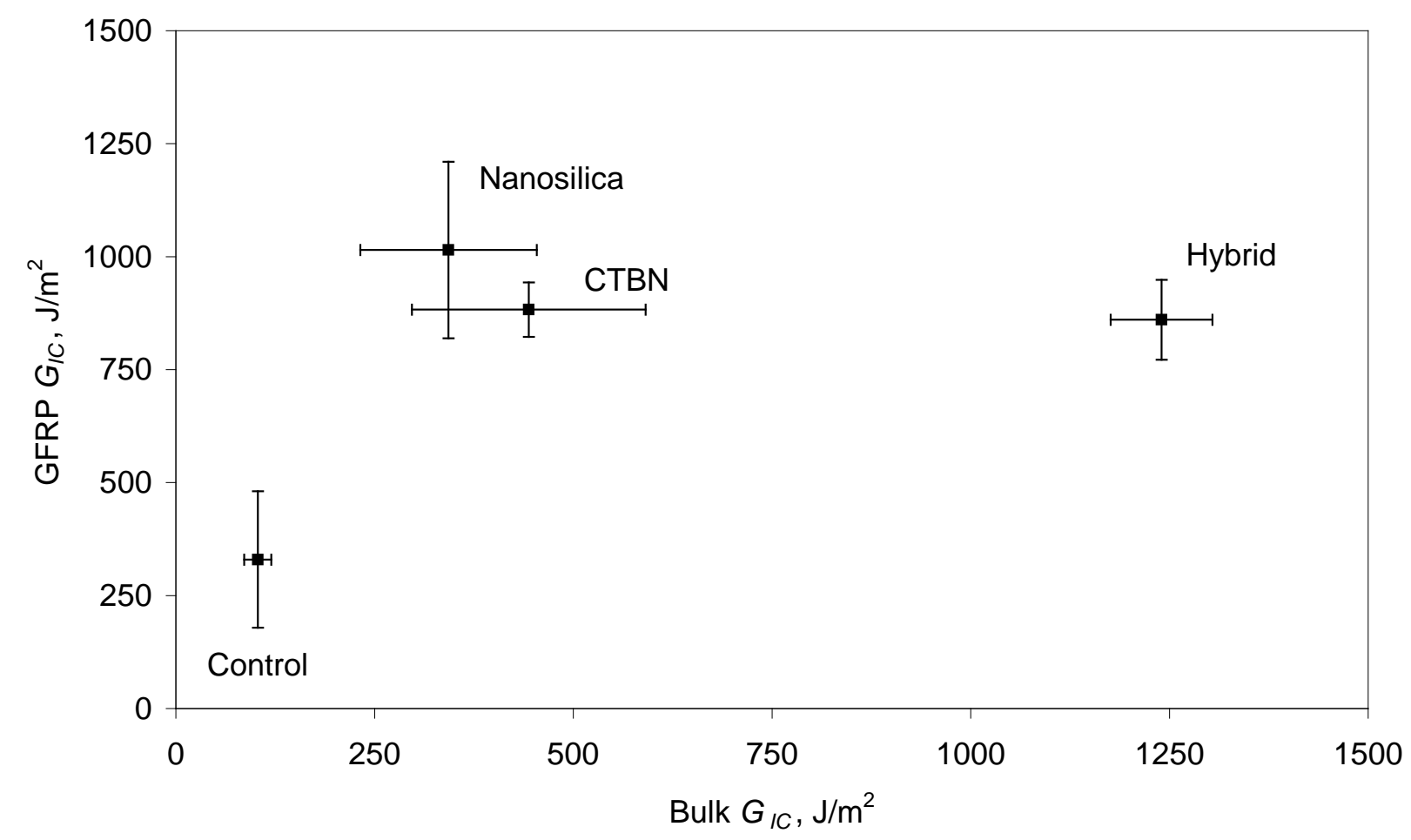

Figure 1. Interlaminar initiation values of $G_{I C}$ for the GFRP composites vs $G_{I C}$ for the bulk matrix. Bulk data from [13].

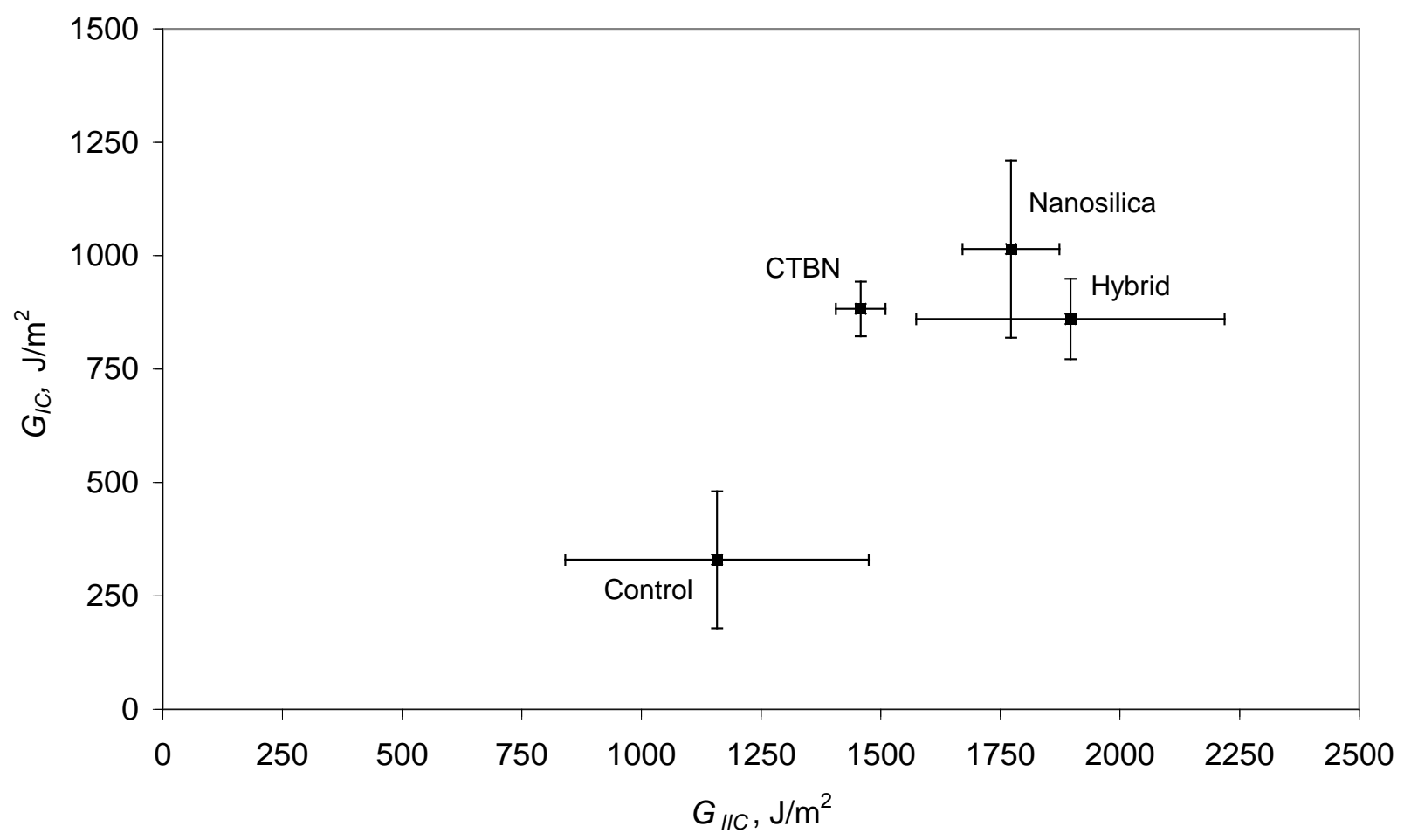

Figure 2. Interlaminar initiation values of $G_{I C}$ vs $G_{I I C}$ for the GFRP composites. 
